\title{
Adrenergic and Dopaminergic Control of the Canine Paw Microcirculation ${ }^{1}$
}

\author{
Eric D. Endean, M.D., Sunil K. Mukhopadhyay, Ph.D., Lit K. Fung, M.D., \\ JACK L. CRONENWETT, M.D., JAMES C. STANLEY, M.D., \\ AND S. MARTIN LINDENAUER, M.D. \\ Department of Surgery, Division of Peripheral Vascular Surgery, University of Michigan, and Peripheral Vascular \\ Research Laboratory, Veterans Administration Medical Center, Ann Arbor, Michigan 48109
}

Submitted for publication November 8, 1984

\begin{abstract}
Basal isolated canine paw blood flow was equally distributed between arteriovenous anastomosis (AVA) and capillary circulations. Norepinephrine decreased AVA flow by $92 \%$ and capillary flow by $41 \%$. Dopamine significantly reduced AVA flow by $94 \%$ compared to baseline with a $37 \%$ reduction in capillary flow. However, with $\alpha$-adrenergic blockade dopamine decreased AVA flow $66 \%$ while capillary flow increased $42 \%$. Isoproterenol increased capillary flow almost twofold and appeared to decrease AVA flow, although the latter was statistically insignificant. Differential effects of adrenergic and dopaminergic agonists on canine paw AVA and capillary blood flow suggest the existence of independent regulation of these components of the microcirculation. O 1986 Academic Press, Inc.
\end{abstract}

Terminal vessels of the microcirculation are comprised of capillaries and arteriovenous anastamoses (AVA). AVA are naturally occurring connections between arterioles and venules that bypass the nutrient capillary bed, whose function is thought to be controlled through neural and hormonal mechanisms. Both adrenergic and dopaminergic receptors have been identified and are considered a part of these control mechanisms $[2,4,9,11,16]$.

AVA and capillaries are found in the skin and subcutaneous tissue of extremities in humans, and in the paw pad of dogs and other animals. AVA have not been identified in muscle. The terminal vessels of the microcirculation in muscle are comprised primarily of capillaries [15]. Because most of the blood flow in the dog hindlimb perfuses muscle, the baseline flow through $\mathrm{AVA}$ is low, comprising 4 to $9 \%$ of total hindlimb blood flow $[6,7]$. With sympathetic stimulation or $\alpha$-adrenergic blockage, AVA have been shown to shunt as much as $25 \%$ of the total hindlimb flow [6].

To accurately measure the effects of vasoactive substances on both capillary and AVA

\footnotetext{
' Presented at the Annual Meeting of the Association for Academic Surgery, San Antonio, Texas, October 31November 3, 1984.
}

flow, a model was developed with isolated arterial and venous circulations of the canine hind paw. In this particular preparation AVA comprise a much greater portion of the terminal vessels of the microcirculation than in the intact canine hindlimb, and thus make small changes in AVA flow easier to quantitate. This model was used to examine the microcirculatory effects of continuous intraarterial infusions of norepinephrine, isoproterenol, and dopamine.

\section{METHODS}

The hind paw of 22 conditioned, healthy, adult mongrel dogs of both sexes, weighing $18-32 \mathrm{~kg}$, was utilized for this study. Dogs were anesthetized with an initial intravenous bolus of sodium pentobarbitol $(27.5 \mathrm{mg} / \mathrm{kg})$ and maintained by a continuous infusion of this drug $(5-7 \mathrm{mg} / \mathrm{kg} / \mathrm{hr})$. All dogs were intubated and ventilated to provide stable arterial blood gases. An esophageal temperature probe was placed and a normal core temperature was maintained with a heating mattress and an overhead heat lamp controlled by a servomechanism. A Swan-Gantz thermodilution catheter was passed into the pulmonary artery. Cardiac outputs were measured using an Ed- 
wards 9520A computer. Mean arterial blood pressure was measured through a catheter inserted in the brachial artery.

The right femoral artery and vein were isolated through a groin incision (Fig. 1). A second incision was made at the ankle joint and the cranial-tibial artery and a superficial metatarsal vein were isolated. An intravenous bolus of heparin $(300 \mathrm{U} / \mathrm{kg})$ was then administered. The femoral artery was directly cannulated with polyethylene tubing (inside diameter $3.0 \mathrm{~mm}$ ), ligating the femoral artery just distal to the cannula site. This tubing was connected in series with an in-line electromagnetic flow probc, two " $T$ " connectors, and a 16-gauge Silastic catheter. The cranial-tibial artery was ligated at the ankle joint and the distal artery was cannulated with the distal end of the previously placed 16-gauge Silastic catheter. This system provided arterial flow directly from the femoral artery to the cranialtibial artery. One " $T$ " connector was used for intermittent injection of microspheres as well as monitoring of mean arterial pressure in the

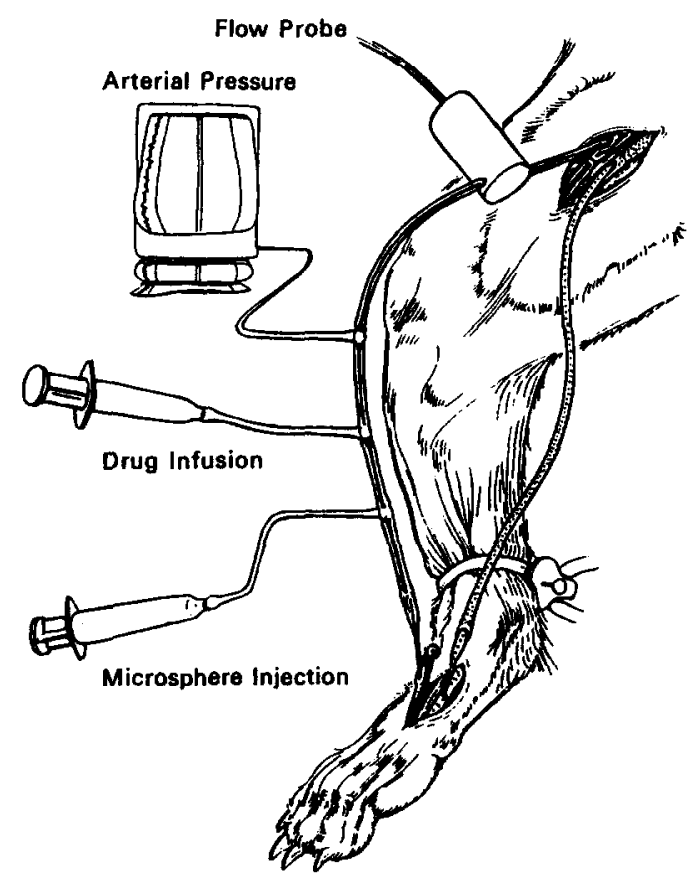

Fig. 1. Artists illustration of isolated canine paw pad preparation utilized to directly measure AVA and capillary blood flow. paw. The other "T" connector was used for continuous intraarterial infusions of various vasoactive substances.

The superficial metatarsal vein was directly cannulated with a 16-gauge Silastic catheter, ligating the vein cephalad. A "T" connector and polyethylene tubing (inside diameter 3.0 $\mathrm{mm}$ ) were connected in series. The femoral vein was then cannulated with the polyethylene tubing, ligating the femoral vein caudally, thus isolating the venous drainage from the paw. The venous "T" connector was used to monitor venous pressure and for the injection of microspheres for shunt calculation. Collatcral blood flow to the paw was eliminated by applying a tourniquet just proximal to the ankle joint. Paw temperature was monitored using a temperature probe placed subcutaneously in the paw pad. Paw temperature was maintained at $37^{\circ} \mathrm{C}$ with an overhead heating lamp. Systemic and paw arterial pressure, paw venous pressure, and total paw blood flow were continuously monitored on a Hewlett-Packard multichannel recorder.

Arteriovenous shunting in the canine paw was measured directly using albumin microspheres labeled with ${ }^{99 \mathrm{~m}} \mathrm{Tc}$ (3M Company). These microspheres had a mean diameter of $20 \mu \mathrm{m}$. A scintillation detector was placed over the thorax and shielded to eliminate spurious radioactivity. Microspheres $(12,500)$, suspended in $0.1 \mathrm{ml}$ of normal saline, were sonicated and injected in the femoral arterial port. Radioactivity in the syringe was measured prior to and immediately after injection, thus allowing for determination of the exact amount of radioactivity injected.

Microspheres of the size used in this study $(20 \mu \mathrm{m})$ are trapped in paw capillaries but pass through paw AVA larger than $20 \mu \mathrm{m}$ in diameter. They are subsequently trapped in pulmonary capillaries where they are measured by the scintillation detector. At the conclusion of the experiment, a similar number of microspheres were injected through the venous port, all of which were trapped in the pulmonary capillaries, thus representing " $100 \%$ shunting." The relative paw AV shunt was then calculated by 
\% AV shunt

$$
=\frac{\mathrm{cpm} \text { arterial/radioactivity injected }}{\mathrm{cpm} \text { venous/radioactivity injected }}
$$

$\times 100 \%$;

where $\mathrm{cpm}=$ net counts per minute detected over the thorax; radioactivity $=$ net millicuries isotope injected; the AVA and capillary paw flows were calculated by; AVA flow $=$ total paw blood flow $\times \%$ AV shunt $/ 100$; and capillary flow = total paw blood flow - AVA flow.

Intraarterial infusion of vasoactive substances was begun after allowing at least 20 min for the system to become hemodynamically stable. Drugs studied were diluted in 5\% dextrose in water to a given concentration, and infused intraarterially into the isolated paw at a constant rate $(0.5 \mathrm{ml} / \mathrm{min})$ using a Harvard infusion pump. All drugs were given in increasing concentrations and microspheres were injected $10 \mathrm{~min}$ following initiation of the infusion. Each incremental drug concen- tration was begun immediately after measurements had been obtained with the previous dose. Drugs tested were norepinephrine $(n=5)$ and isoproterenol $(n=5)$ at concentrations of $0,0.5,1.0,2.0,4.0,10.0 \mathrm{ng} / \mathrm{kg} / \mathrm{min}$; and dopamine $(n=6)$ in concentrations of $0,1.0$, $5.0,10.0,50.0,100.0$, and $500.0 \mathrm{ng} / \mathrm{kg} / \mathrm{min}$. Results were analyzed for statistical significance between baseline and values obtained at the maximum dose infused using the Student paired $t$ test.

\section{RESULTS}

Arterial $P_{2}, \mathrm{pH}$, and $P \mathrm{O}_{2}$ did not change significantly during the experiment (Table 1). No significant changes occurred in mean systemic or mean paw pressure in the norepinephrine and dopamine groups, although these parameters fell in the isoproterenol group. The baseline total paw blood flow varied in each group of animals ( 37 to $53 \mathrm{ml} /$ min) but the percentage of flow in AVA was

TABLE 1

MEASUREMENTS BEFORE AND AFTER THE FiNAL DOSE OF INTRAARTERIAL NOREPINEPHRINE, ISOPROTERENOL, AND DOPAMINE

\begin{tabular}{|c|c|c|c|c|}
\hline & & Norepinephrine & Isoproterenol & Dopamine \\
\hline $\begin{array}{l}\text { Cardiac output } \\
\text { (liters/min) }\end{array}$ & $\begin{array}{l}\text { Initial } \\
\text { Final }\end{array}$ & $\begin{array}{l}3.93 \pm .54 \\
2.72 \pm .31^{*}\end{array}$ & $\begin{array}{l}3.95 \pm .31 \\
3.12 \pm .33^{*}\end{array}$ & $\begin{array}{c}4.6 \pm .34 \\
3.31 \pm .21^{*}\end{array}$ \\
\hline $\mathrm{pH}$ & $\begin{array}{l}\text { Initial } \\
\text { Final }\end{array}$ & $\begin{array}{l}7.38 \pm .04 \\
7.33 \pm .01\end{array}$ & $\begin{array}{l}7.36 \pm .03 \\
7.34 \pm .06\end{array}$ & $\begin{array}{l}7.45 \pm .19 \\
7.45 \pm .03\end{array}$ \\
\hline$P_{2}(\mathrm{~mm} \mathrm{Hg})$ & $\begin{array}{l}\text { Initial } \\
\text { Final }\end{array}$ & $\begin{array}{r}101.3 \pm 4.4 \\
92.0 \pm 5.6\end{array}$ & $\begin{array}{l}81.5 \pm 4.4 \\
71.7 \pm 15.0\end{array}$ & $\begin{array}{l}96.5 \pm 4.4 \\
93.5 \pm 5.8\end{array}$ \\
\hline $\mathrm{PCO}_{2}(\mathrm{~mm} \mathrm{Hg})$ & $\begin{array}{l}\text { Initial } \\
\text { Final }\end{array}$ & $\begin{array}{l}37.3 \pm 3.8 \\
38.5 \pm 1.5\end{array}$ & $\begin{array}{l}37.5 \pm 3.8 \\
41.3 \pm 8.3\end{array}$ & $\begin{array}{l}27.7 \pm 1.7 \\
29.2 \pm 2.2\end{array}$ \\
\hline $\begin{array}{l}\text { Core } \\
\text { temperature }\left({ }^{\circ} \mathrm{C}\right)\end{array}$ & $\begin{array}{l}\text { Initial } \\
\text { Final }\end{array}$ & $\begin{array}{l}37.1 \pm .43 \\
37.8 \pm .51^{*}\end{array}$ & $\begin{array}{l}37.7 \pm .50 \\
38.8 \pm .42^{*}\end{array}$ & $\begin{array}{l}38.3 \pm .37 \\
39.2 \pm .31^{*}\end{array}$ \\
\hline $\begin{array}{l}\text { Paw } \\
\quad \text { temperature }\left({ }^{\circ} \mathrm{C}\right)\end{array}$ & $\begin{array}{l}\text { Initial } \\
\text { Final }\end{array}$ & $\begin{array}{l}36.6 \pm .44 \\
36.7 \pm .26^{*}\end{array}$ & $\begin{array}{l}36.4 \pm .64 \\
37.4 \pm .31^{*}\end{array}$ & $\begin{array}{l}35.6 \pm .21 \\
36.2 \pm .23^{*}\end{array}$ \\
\hline $\begin{array}{l}\text { Systcmic blood pressure } \\
(\mathrm{mm} \mathrm{Hg})\end{array}$ & $\begin{array}{l}\text { Initial } \\
\text { Final }\end{array}$ & $\begin{array}{l}157 \pm 9 \\
150 \pm 8\end{array}$ & $\begin{array}{l}163 \pm 9 \\
152 \pm 7^{*}\end{array}$ & $\begin{array}{l}146 \pm 5 \\
148 \pm 5\end{array}$ \\
\hline $\begin{array}{l}\text { Paw blood pressure } \\
\text { (mm Hg) }\end{array}$ & $\begin{array}{l}\text { Initial } \\
\text { Final }\end{array}$ & $\begin{array}{l}134 \pm 9 \\
134 \pm 11\end{array}$ & $\begin{array}{l}121 \pm 8 \\
103 \pm 8^{*}\end{array}$ & $\begin{array}{l}137 \pm 5 \\
134 \pm 6\end{array}$ \\
\hline
\end{tabular}

a Mean \pm SEM.

$* P<0.05$. 
relatively constant in each group (48\%). Cardiac output fell in each group by the end of the experiment. Both paw and core temperature increased slightly but significantly when initial temperature was compared to final temperature in all groups (Student's paired $t$ test).

Infusions of norepinephrine in increasing concentrations resulted in a progressive decrease in total paw blood flow to $66 \%$ of baseline ( 53 to $18 \mathrm{ml} / \mathrm{min} ; P \leqslant 0.001$ ), as well as a decrease in both capillary and AVA flow. The response appeared to be more pronounced on the AVA decreasing flow by $92 \%$ ( 26 to $2 \mathrm{ml} / \mathrm{min} ; P \leqslant 0.023$ ) compared to the capillary flow which decreased $41 \%$ (27 to 16 $\mathrm{ml} / \mathrm{min} ; P \leqslant 0.048$; Fig. 2).

Isoproterenol infusions resulted in a $20 \%$ increase in total paw blood flow ( 48 to $58 \mathrm{ml} /$ $\min ; P \leqslant 0.056$ ). Capillary flow increased almost twofold ( 25 to $48 \mathrm{ml} / \mathrm{min} ; P \leqslant 0.05$ ) while there was a $35 \%$ decrease in AVA flow ( 23 to $15 \mathrm{ml} / \mathrm{min} ; P \geqslant 0.2$ ) that was statistically insignificant (Fig. 3).

Dopamine infusions caused a progressive decrease in total paw blood flow to $65 \%$ of baseline ( 37 to $13 \mathrm{ml} / \mathrm{min} ; P \leqslant 0.003$ ). AVA flow was significantly reduced to $94 \%$ of baseline (18 to $1 \mathrm{ml} / \mathrm{min} ; P \leqslant 0.015$ ) with a statistically insignificant decrease in capillary flow of 37\% (19 to $12 \mathrm{ml} / \mathrm{min} ; P>0.3$ ), (Fig. 4). The results of all drug infusions were able to be plotted as different dose response curves, with statistical significance assessed at the maximum dosage infused compared to baseline.

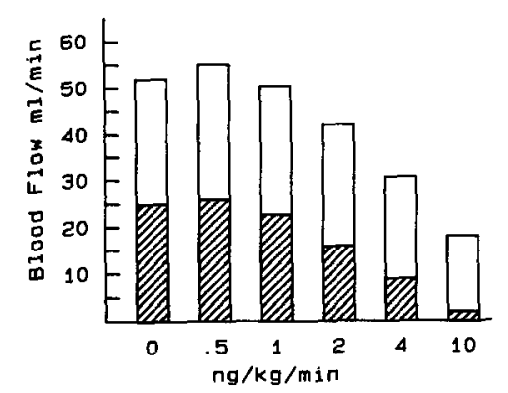

FIG. 2. Effects of increasing doses of norepinephrine on the distribution of blood flow in the isolated paw pad. 聯, AVA; $\square$, CAP.

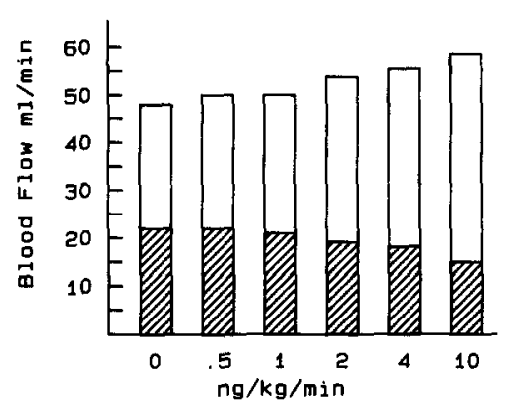

FIG. 3. Effect of increasing doses of isoproterenol on the distribution of blood flow in the isolated paw pad. AVA; $\square$, CAP.

\section{DISCUSSION}

Arteriovenous anastomoses previously have been described on the basis of their unique function or specific anatomy. AVA, in contrast to capillaries, do not allow exchange of nutrients and metabolic products with the surrounding interstitial fluid. AVA can also be distinguished from capillaries by their ability to dilate to diameters as great as $70 \mu \mathrm{m}$, while capillaries are thought incapable of dilating beyond $10 \mu \mathrm{m}$ diameter [14].

We have chosen in this study to define AVA as communications between arterioles and venules that are larger than $20 \mu \mathrm{m}$. It has been shown that a small percentage (4 to $9 \%$ ) of total canine hindlimb blood flow normally passes through AVA. Thus, experiments which have assessed the effect of vasoactive substances on the entire hind limb may not show an effect on AVA, (even when attempts have been made to specifically measure them) because they comprise such a small proportion of the total hindlimb blood flow. In the model currently utilized there were a large number of AVA in the baseline state, with the baseline percentage shunt being $48 \%$ as compared to 4 to $9 \%$ in the total hindlimb model $[6,7]$. The technique and validity of AVA flow measurement by microsphere injection have been described and discussed elsewhere [13, 15]. Care was taken to maintain constant temperature, arterial pH, arterial $P_{2}$, and level of anesthesia, as these are known to induce variability in shunt measurements [11]. Cardiac output decreased in our preparation over time and may be explained by a myocardial depressant 


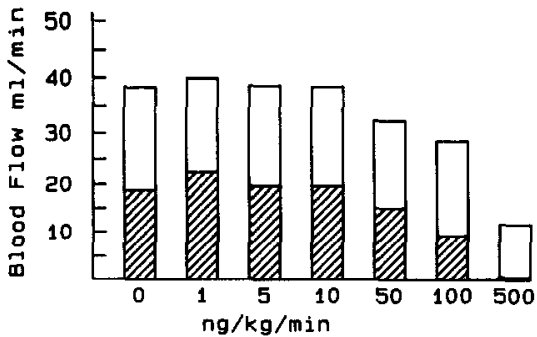

FIG. 4. Effect of increasing doses of dopamine on the distribution of blood flow in the isolated paw pad. AVA; $\square$, CAP.

effect due to prolonged pentobarbitol anesthesia.

Spence and colleagues using a canine hindlimb preparation and giving intraarterial norepinephrine or isoproterenol in a bolus fashion observed that norepinephrine decreased flow through both capillaries and AVA with a greater effect on AVA flow [16]. They also noted that isoproterenol caused large increases in capillary flow with no change in AVA flow. These observations led them to conclude that changes in AVA flow were mediated by adrenergic receptors. Our work is consistent with their observations although our data suggest that isoproterenol may decrease AVA flow. However, this latter change was not statistically significant. It is possible that with a higher percentage of flow through AVA in the paw, that smaller changes in this flow became apparent.

Cohen and Coffman measured total finger blood flow in human subjects plethysmographically and then infused norepinephrine intraarterially to produce vasoconstriction [5]. After a new steady state was reached, an additional infusion of isoproterenol was begun that dramatically increased total finger blood flow. By observing no change in the clearance of subcutaneously injected $\mathrm{Na}^{131} \mathrm{I}$ before or after the isoproterenol infusion, they concluded that the increased blood flow produced by isoproterenol was caused by an increase in AVA flow. This led them to suggest that $\beta$ adrenergic receptors were important in the regulation of AVA flow. Our results differ from their hypothesis. While isoproterenol caused an increase in total paw blood flow, this appeared due to an increase in capillary flow without a statistically significant change in AVA flow. In addition to possible species variation, this difference may be explained by the technique of measuring AVA and capillary flow in the extremity. We have directly measured flow through these pathways, while Cohen and Coffman distinguished AVA from capillary flow indirectly. Also in the current study we measured the effect of isoproterenol in the absence of exogenous agonists; Cohen and Coffman assessed the effect of isoproterenol on the finger tip previously vasoconstricted by norepinephrine.

Dopamine injected into the femoral artery has been shown to result in increased femoral artery blood flow in anesthetized dogs, and it is thought that there are specific dopamine vasodilator receptors in the vascular bed of the hindlimb [1]. Other studies suggest that autonomic axons release dopamine or a related substance which functions as a neurotransmitter causing vasodilation [3]. These former studies did not investigate whether dopamine affected primarily capillary flow or AVA flow.

Dopamine, in the current study, caused a statistically significant decrease in both total blood flow and AVA flow. Capillary flow also fell but to a lesser extent that was not statistically significant. In this model, there was no evidence of dopamine-induced vasodilation although changes similar to that seen with the $\alpha$-agonist, norepinephrine, were observed. Because the model contains almost no muscle and assesses changes primarily in a cutaneous vascular bed, a dopamine-mediated vasodilatory effect on vessels supplying muscle cannot be ruled out even though the maximum dose used in our current study was approximately a fifth the maximum dose used in prior studies evaluating the effects of intraarterial dopamine.

Further experiments ( $n=6)$ using the model described in this paper have been done to clarify the effect of dopamine on the microcirculation. Intraarterial infusion of dopamine, at various concentrations, was carried out after $\alpha$-adrenergic blockade had been obtained with continuous phentolamine infusion (200-600 $\mathrm{ng} / \mathrm{kg} / \mathrm{min}$ ). Completeness of blockade was determined by the lack of response to a test 


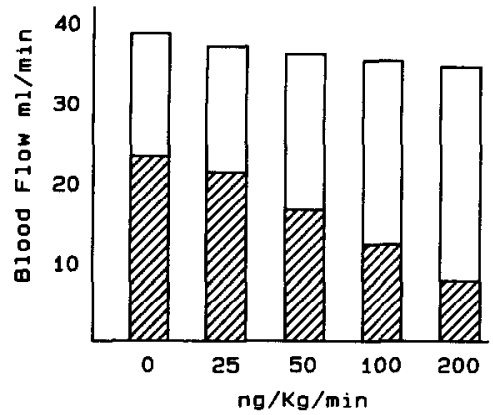

FIG. 5. Effect of increasing doses of dopamine (with phentolamine infusion) during continuous $\alpha$-adrenergic blockage on the distribution of blood flow in the isolated paw pad. AVA; $\square$, CAP.

dose of $5 \mathrm{ng}$ of norepinephrine. Preliminary results indicate that flow through AVA decreased $66 \%(23.4 \pm 2.2$ to $8 \pm 1.2 ; P \leqslant 0.001)$ while capillary flow increased $42 \%$ (15.6 \pm 2.4 to $27 \pm 2.8 ; P \leqslant 0.001$ ). In this experiment, total blood flow decreased slightly $(39 \pm 2.3$ to $35 \pm 2.1 ; P \leqslant 0.05$; Fig. 5). These results suggest that with $\alpha$-adrenergic blockade, dopamine infusion causes a greater divergence of effects on AVA compared to capillary flow and less of a decrease in total flow compared to dopamine infusion without $\alpha$ blockade. Vasodilator and vasoconstrictor effects have been noted with direct intraarterial dopamine infusion that are related both to the specific receptor bed and to the dose level infused [8, $10,12]$.

Data from the current experiment support the hypothesis that there may be independent regulation of AVA and capillary flow in the canine microcirculation. Further studies are being done using the model described to define the possible differential effect of other vasoactive substances on capillary and AVA flow.

\section{REFERENCES}

1. Bell, C., Conway, E. L., Lang, W. J., and Padanyi, R. Vascular dopamine receptors in the canine hind limb. Brit. J. Pharmacol 55: 167, 1975.
2. Bell, C., and Lang, W. J. Evidence for dopaminergic vasodilator innervation of the canine paw pad. Brit. J. Pharmacol. 67: 337, 1979.

3. Bell, C., Lang, W. J., and Laska, F. Dopamine-containing axons supplying the arterio-venous anastamoses of the canine paw pad. J. Neurochem. 31: 1329, 1978.

4. Bell, C., and Stubbs, A. Localization of Vasodilator dopamine receptors in the canine hind limb. Brit. $J$. Pharmacol. 64: 253, 1978.

5. Cohen, R. A., and Coffman, J. D. $\beta$-Adrenergic vasodilatory mechanism in the finger. Circ. Res. 49: 1196, 1981.

6. Cronenwett, J. L., Zelenock, G. B., Whitehouse, W. M., Stanley, J. C., and Lindenauer, S. M. The effect of sympathetic innervation on canine muscle and skin blood flow. Arch. Surg. 118: 420, 1983.

7. Delaney, J. P., Zanick, D. C., and Scarpino, J. H. Control of arteriovenous shunting. Surg. Forum. 23: 241, 1972.

8. Eble, J. N. A proposed mechanism for the depressor effect of dopamine in the anaesthetized dog. J. Pharmacol. Exp. Ther. 145: 64, 1964.

9. Glick, G., Epstein, S., Wechsler, A. S., and Braunwald, E. Physiological differences between the effects of neuronally released and blood borne norepinephrine on beta adrenergic receptors in the arterial bed of the dog. Circ. Res. 21: 217, 1967.

10. Goldberg, L. I., and Kohli, J. D. Specific dopamine receptors in vascular smooth muscle. In P. M. Vanhoutte and I. Leusen (Eds.), Vasodilatation. New York: Raven Press, 1981. Pp. 131-140.

11. Greenfield, A. D. M. The circulation through the skin. In Handbook of Physiology, Circulation. Bethesda, Md.: American Physiology Society, 1963. Sect. 2, Vol. II, Chap. 39, pp. 1325-1351.

12. Higgins, C. B., Millard, R. W., Braunwald, E., and Vatner, S. F. Effects and mechanisms of action of dopamine on regional hemodynamics in the conscious dog. Amer. J. Physiol. 225: 432, 1973.

13. Lopez-Majano, V., Rhodes, B. A., and Wagner, H. N. Arteriovenous shunting in extremities. J. Appl. Physiol. 27: 782, 1969.

14. Neims, J. D. Functional anatomy of skin related to temperature regulation. Fed. Proc. 22: 93, 1963.

15. Rhodes, B. A., Rutherford, R. B., Lopez-Majano, V., Gregson, N. D., and Wagner, H. N. Arteriovenous shunt measurements in extremities. J. Nucl. Med. 13: $357,1972$.

16. Spence, R. J., Rhodes, B. A., and Wagner, H. N. Regulation of arteriovenous anastamotic and capillary blood flow in the dog leg. Amer. J. Physiol. 222: 326, 1972. 